\title{
FEASIBLE METHOD TO FABRICATE A NICKEL-NANODOT MASK ON A SILICON SUBSTRATE WITH CONVENTIONAL THERMAL ANNEALING
}

\author{
IZVEDLJIVA METODA KONVENCIONALNE TERMIČNE \\ OBDELAVE ZA IZDELAVO MASK NA OSNOVI NIKLJEVIH \\ NANOPIK NA SILICIJEVI PODLAGI
}

\author{
Xuping Kuang ${ }^{1}$, Jili Tian², Hui Guo ${ }^{1}$, Yi Hou ${ }^{1}$, Huayu Zhang ${ }^{2}$, Tiejun Liu ${ }^{3}$ \\ ${ }^{1}$ Shenzhen Selen Science \& Technology Co., Ltd, Shenzhen 518055, China \\ ${ }^{2}$ Shenzhen Key Laboratory of Advanced Materials, Shenzhen Graduate School, Harbin Institute of Technology, Shenzhen 518055, China \\ 3 Shenzhen Graduate School, Harbin Institute of Technology, Shenzhen 518055, China \\ tianjili1987@163.com
}

Prejem rokopisa - received: 2017-01-12; sprejem za objavo - accepted for publication: 2017-10-26

doi: $10.17222 / \mathrm{mit} .2017 .006$

\begin{abstract}
In this paper, a simple and feasible method to fabricate a Ni-nanodot mask on a silicon substrate is reported. Without using a high-cost rapid thermal annealing (RTA) furnace, this method was based on the conventional thermal annealing of a Ni layer deposited on a Si substrate. In addition, the influences of the Ni-layer thickness and annealing conditions on the size and density of the Ni nanodots were systematically investigated. The as-prepared Ni nanodots were well distributed, having a uniform size and a regular spherical shape. Moreover, a Si nanopillar array could be fabricated by inductively coupled plasma (ICP) etching using the as-obtained Ni-nanodot array mask.

Keywords: Ni nanodot, conventional thermal annealing, ICP, Si nanopillar

V članku avtorji opisujejo enostavno in izvedljivo metodo za izdelavo mask iz Ni-nanopik na Si podlagi. Pri tem niso uporabili drage peči za hitro termično obdelavo, temveč konvencionalni postopek termičnega žarjenja Ni-plasti nanešene na Si-podlago. Sistematično so tudi raziskali vpliv debeline Ni-plasti in pogojev žarjenja na velikost in gostoto Ni-nanopik. Le-te so bile enakomerno razporejene, bile so enake velikosti in pravilne polkroglične oblike. Poleg tega so avtorji članka pokazali, da se lahko izdelajo matrice sestavljene iz Si-nanostebričkov s pomočjo jedkanja z induktivno sklopljeno plazmo (angl. ICP) in uporabo izdelanih Ni-nanopik.

Ključne besede: Ni -nanopike, konvencionalna termična obdelava, ICP, Si-nanostebrički
\end{abstract}

\section{INTRODUCTION}

In the past few decades, there was much interest in silicon nanostructures due to their potential electronic and photonic applications such as biosensor, ${ }^{1}$ gas detector, ${ }^{2}$ memory cell, ${ }^{3}$ photovoltaic crystal structures, ${ }^{4}$ and field-emission light-emitting devices. ${ }^{5}$ Typically, electron-beam (E-beam) lithography together with inductively coupled plasma (ICP) etching or reactive-ion etching (RIE) process is the most successful and dominant method for the fabrication of $\mathrm{Si}$ nanostructures. ${ }^{6,7}$ However, we need more accurate lithography when silicon nanostructures reduce to a small size, particularly on the nanoscale, which involves high costs and is not suitable for a large-area fabrication.

Therefore, a simple, cost-effective and non-lithography method using self-assembled Ni nanodots as the etching mask has been proposed for many years. ${ }^{8}$ It is well known that the self-aggregation of the evaporated $\mathrm{Ni}$ film on Si substrates allows it to function as the etching mask for the fabrication of high-aspect-ratio $\mathrm{Si}$ nanostructures, as well as $\mathrm{Al}, \mathrm{Au}$, and $\mathrm{Ag} .{ }^{9}, 10$ Furthermore, J. Zhu et al. ${ }^{11}$ employed a Ni-nanodot mask to fabricate GaN-based nanopillar light-emitting diodes. However, the preparation of Ni nanodots on Si substrates still has some limitations. Many research groups reported rapid thermal annealing (RTA) of the Ni layer deposited on silicon substrates. ${ }^{12-15}$ Other studies investigated the introduction of a thin $\mathrm{SiO} 2$ buffered layer between the $\mathrm{Si}$ substrate and the Ni film. ${ }^{12,14,15}$ Recently, I. Levchenko et al. ${ }^{16}$ have suggested that $\mathrm{Ni}$-nanodot arrays on a $\mathrm{Si}$ surface can be obtained using a plasma-assisted method. In general, either a high-cost RTA furnace or a complex process control is required in most cases.

In this paper, we report on a simple and feasible method to prepare the Ni-nanodot mask on a silicon substrate. In this process, well-distributed Ni-nanodot arrays were prepared by conventionally annealing Ni films deposited on the Si substrate using a common tube furnace instead of an expensive RTA furnace. The Ni nanodots were approximately spherical with a uniform size and a regular shape. Subsequently, we fabricated a $\mathrm{Si}$ nanopillar by dry-etching the $\mathrm{Si}$ substrate using the as-prepared Ni-nanodot array layer. 


\section{EXPERIMENTAL PART}

In order to obtain a Ni-nanodot array on the $\mathrm{Si}$ substrate, we performed conventional annealing of the $\mathrm{Ni}$ films deposited on a silicon wafer. Figure 1 shows a schematic illustration of the experimental procedures for the fabrication of the Ni-nanodot mask on the $\mathrm{Si}$ substrate. Firstly, a very thin Ni layer was deposited on the $\mathrm{Si}$ (111) substrate by sputtering the Ni target using a JGP-450a radio-frequency magnetron-sputtering system. Prior to deposition, the silicon substrate was cleaned during the RCA cleaning process in order to remove dust particles and native oxide. A 99.999-\% pure Ni target with a 2 in. diameter and the Ar plasma (99.999 \%) were used for the sputtering. The distance between the substrate and the target was $60 \mathrm{~mm}$. The base pressure was $4 \times 10^{-4} \mathrm{~Pa}$ and the flow rate of Ar was $20 \mathrm{~mL} / \mathrm{min}$. Thin Ni films were deposited at a substrate temperature

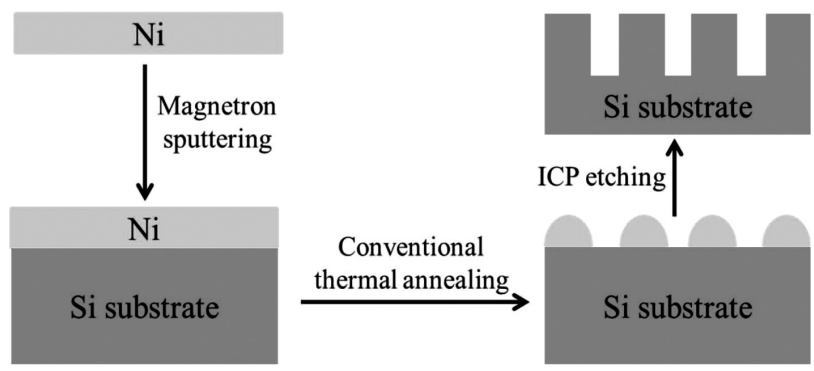

Figure 1: Schematic illustration of the experimental procedures for the fabrication of the Ni-nanodot mask on a Si substrate

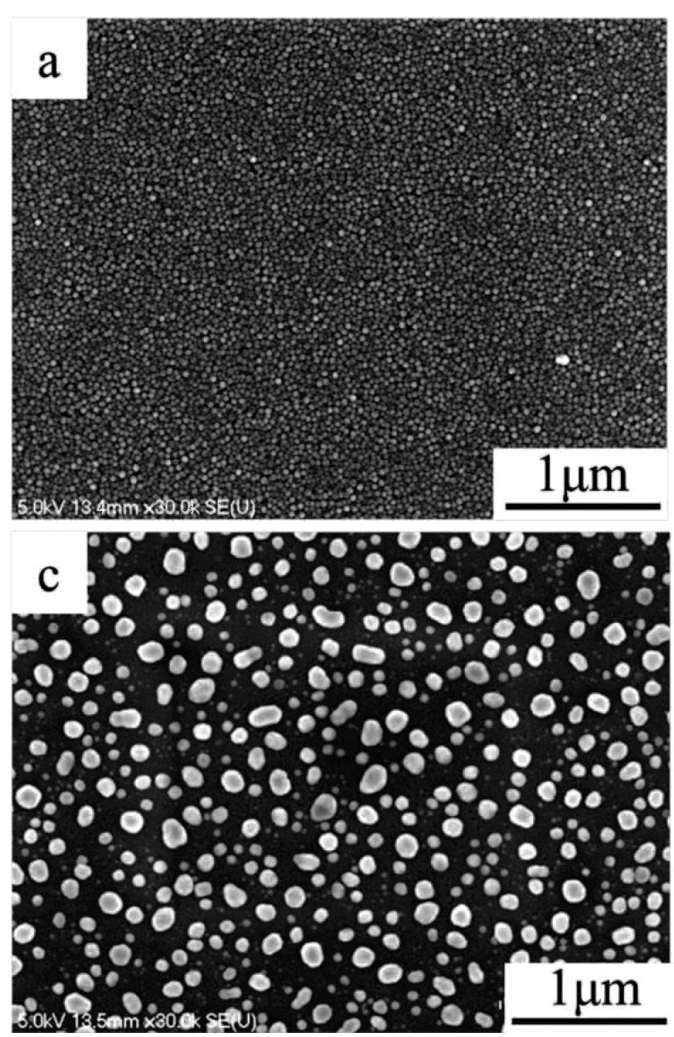

of $20{ }^{\circ} \mathrm{C}$ using different times. The growth velocity of the thin $\mathrm{Ni}$ films was $0.185 \mathrm{~nm} / \mathrm{s}$ and the typical film thickness ranged from $6 \mathrm{~nm}$ to $22 \mathrm{~nm}$. Then, the assputtered $\mathrm{Ni}$ films were annealed in a conventional tube furnace. The heating rate was set to $8{ }^{\circ} \mathrm{C} / \mathrm{min}$, and the films were annealed in $\mathrm{N}_{2}$ at a flow rate of $50 \mathrm{~mL} / \mathrm{min}$ and different temperatures. After annealing, the samples were naturally cooled down to room temperature and taken out for characterization.

For the application of Ni nanodots on the Si substrate, the Si substrate was dry etched in a planar-type inductively coupled plasma (ICP) etching system (Oxford Plasma System 100, ICP 180) at a rf frequency of $13.56 \mathrm{MHz}$ using the as-obtained $\mathrm{Ni}$ nanodots as the nanomask. The ICP and RF power were $1200 \mathrm{~W}$ and 90 $\mathrm{W}$, respectively. The etching gases of $\mathrm{SF}_{6}$ and $\mathrm{CHF}_{3}$ with a condition of $\mathrm{SF}_{6} / \mathrm{CHF}_{3}=7 / 21 \mathrm{~mL} / \mathrm{min}$ were introduced into the reactive chamber through individual electronic mass-flow controllers. The chamber pressure of $1.07 \mathrm{~Pa}$ remained unchanged during the etching duration of $1 \mathrm{~min}$. After the etching, the samples were taken out for characterization.

The sample surface and side-view morphology were investigated with scanning electron microscopy (SEM: HITACHI S-4700).

\section{RESULTS AND DISCUSSION}

Figure 2 shows SEM images of the $\mathrm{Ni}$ nanodots self-aggregating on the silicon substrates and creating

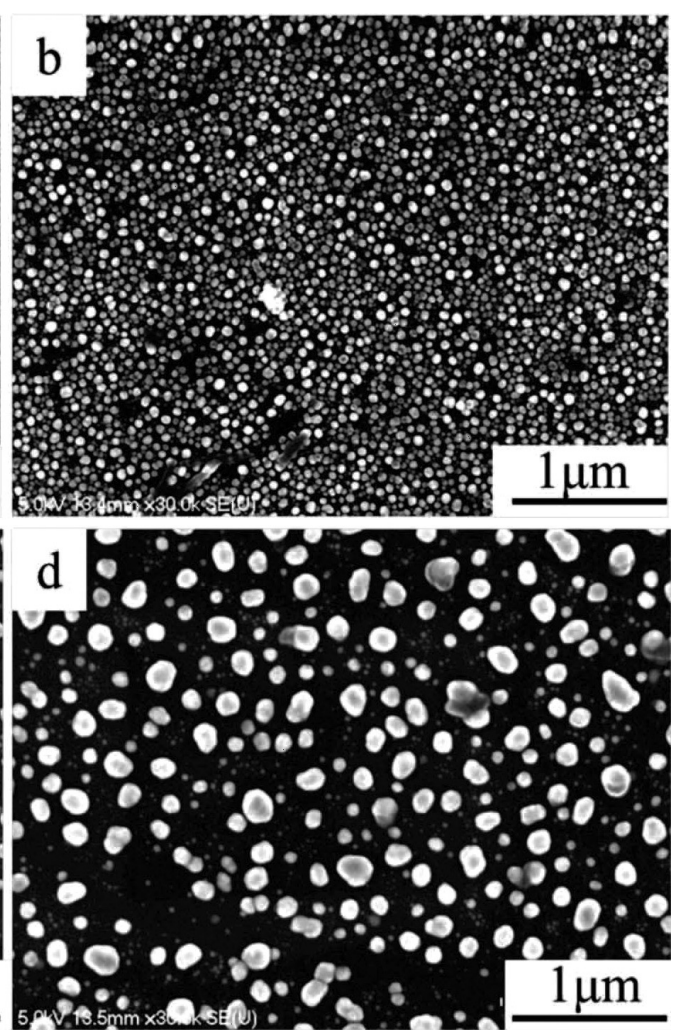

Figure 2: SEM images of the samples with different Ni films after annealing: a) $6 \mathrm{~nm}$, b) $8 \mathrm{~nm}$, c) $14 \mathrm{~nm}$, d) $16 \mathrm{~nm}$ 


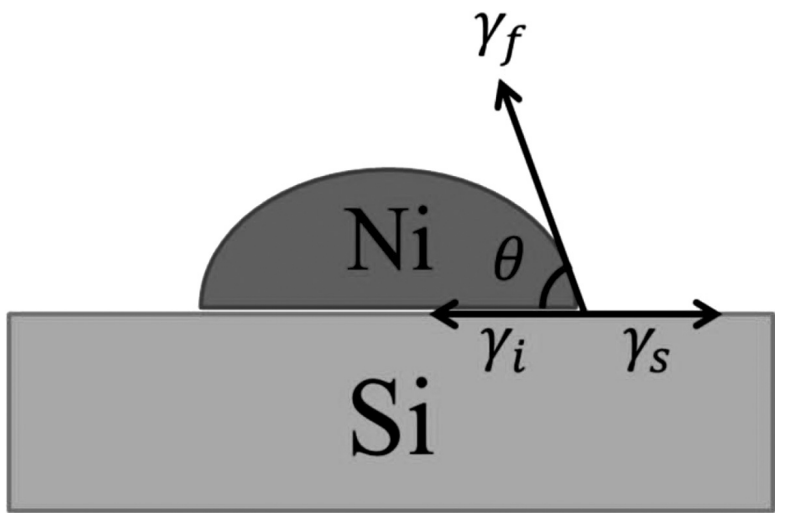

Figure 3: Equilibrium shape of a $\mathrm{Ni}$ island with isotropic surface energy on the Si substrate

as-deposited $\mathrm{Ni}$ layers with different thicknesses after the conventional annealing at $800{ }^{\circ} \mathrm{C}$ for $30 \mathrm{~min}$. As expected, the self-assembly of the Ni nanodots on all the Si substrates can be clearly observed. However, as shown in Figure 1, the array pattern of nanoparticles was strongly affected by the thickness of the Ni films at a given annealing temperature. The average diameter of the nanodots became larger and the average distance between adjacent nanodots was increased while their density was reduced with the increasing $\mathrm{Ni}$-film thickness. In the cases of thicker Ni films, the islands became bigger and the correlation distance became larger due to the Ni nanoclusters merging together, ${ }^{17,18}$ thus reducing the density. Therefore, the process can be controlled by varying the Ni-film thickness influencing the period, size and density of the pattern of the Ni nanodots on a silicon substrate.

In general, the solid-state aggregation of a thin metal film is a phenomenon, allowing the film aggregated to spontaneously form specific-shape particles when reaching a certain temperature below the melting point. A thin $\mathrm{Ni}$ film aggregated to form an island during the annealing is depicted in Figure 3. The driving force is the minimum interfacial free energy between the film and the substrate. The relationship between the interfacial energy of the nanoparticles, taking into account per unit area $\left(\gamma_{\mathrm{f}}\right)$, and that of the substrate $\left(\gamma_{\mathrm{s}}\right)$ is given as Equation (1): ${ }^{19}$

$$
\gamma_{\mathrm{s}}=\gamma_{\mathrm{i}}+\gamma_{\mathrm{f}} \cdot \cos \theta
$$

where $\gamma_{\mathrm{i}}$ is the value of the unit-area energy between the island-like particles and the substrate interface. $\theta$ represents the equilibrium contact angle between the particles and the substrate. It is clearly seen from the Equation (1) that the solid-state aggregation of a $\mathrm{Ni}$ film cannot proceed under the condition of $\gamma_{\mathrm{s}}>\gamma_{\mathrm{i}}+\gamma_{\mathrm{f}} \cdot \cos \theta$ as a thin $\mathrm{Ni}$ film aggregates to form island-like particles when a sufficient driving force is in place.

SEM images of the Ni nanodots self-aggregating on the $\mathrm{Si}$ substrate as a function of the annealing temperature are shown in Figure 4. During this process, the conventional annealing condition for the 12-nm thick Ni layer processed for $30 \mathrm{~min}$ remains unchanged. It is clearly seen that the density of the $\mathrm{Ni}$ nanoparticles gradually decreased, but then reversed for the size with the increasing annealing temperature, which may have
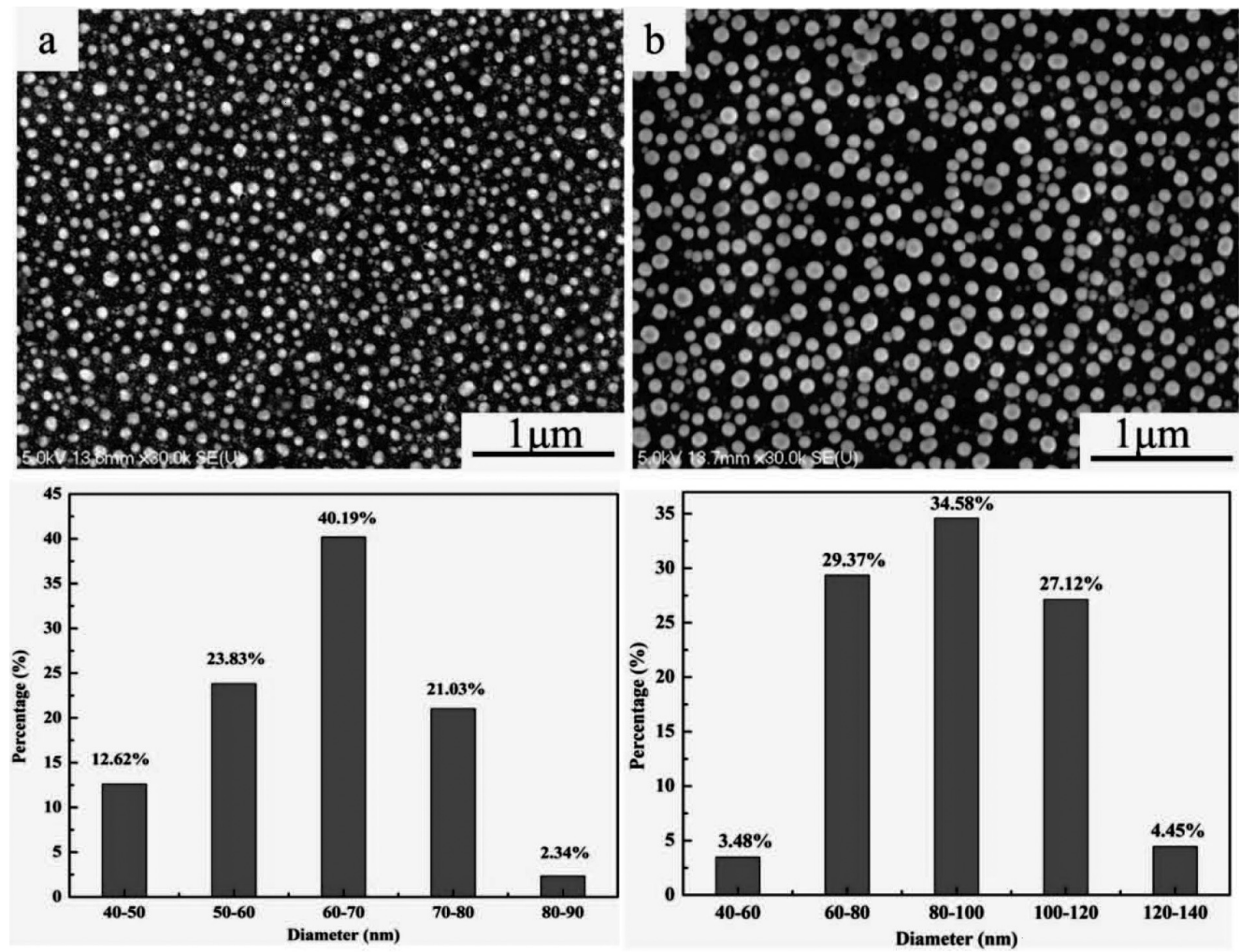

Figure 4: SEM images of Ni nanodots self-aggregating on Si substrates formed by annealing at different temperatures: a) $700{ }^{\circ} \mathrm{C}$ and b) $800{ }^{\circ} \mathrm{C}$ 

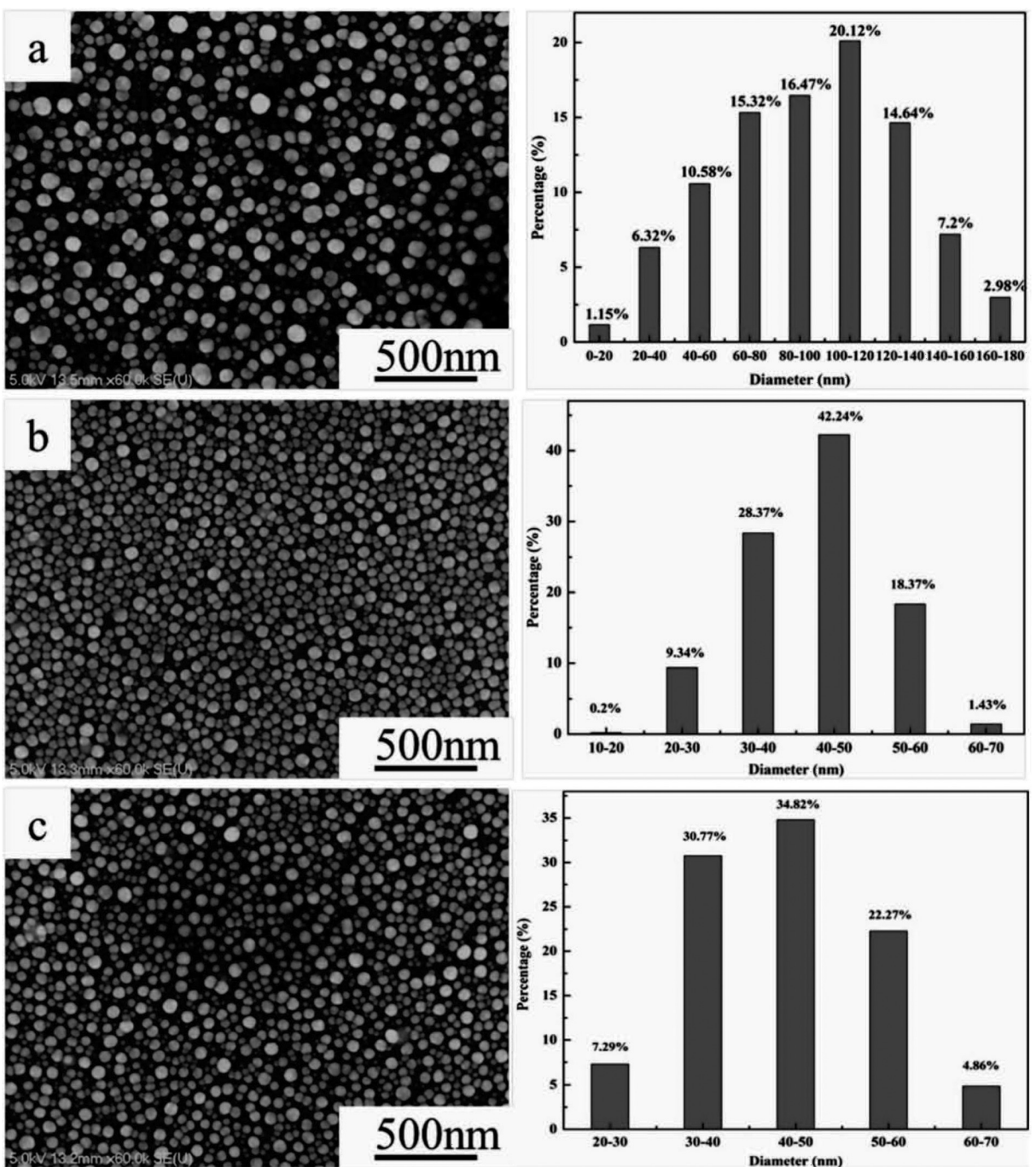

Figure 5: SEM images of self-aggregated Ni nanodots on Si substrates formed by annealing for different durations: a) $15 \mathrm{~min}$, b) $30 \mathrm{~min}$, c) 60 $\min$

been caused due to two reasons: (1) the migration of nickel atoms into the substrate surface was enhanced by a higher temperature, which means that the nickel atoms aggregated on the surfaces of large nanoparticles, further reducing the interfacial energy and achieving the minimum free energy; ${ }^{19}$ (2) meanwhile, the fusion and coarsening behavior towards a small size of the $\mathrm{Ni}$ nanoparticles were enhanced, lowering the free energy, therefore, the small particles eventually merged or grew into larger ones with the increase in the annealing temperature. As a result of the above, the Ni atoms could not migrate over long distances and eventually changed into a strip of particles due to the weaker migration at a lower temperature, which means that more spherical nanoparticles were formed at a higher temperature. In order to obtain Ni nanodots with a uniform size and a regular spherical shape, it is necessary to appropriately increase the annealing temperature.

The effect of the annealing time on the size and density of the self-assembled Ni nanodots was also studied. Figure 5 shows SEM images of the self-assembled
$\mathrm{Ni}$ nanodots on silicon substrates after annealing at $800{ }^{\circ} \mathrm{C}$ for different times. The Ni film initially breaks into large $\mathrm{Ni}$ strips and gradually achieves a spherical shape with the increasing annealing time. In addition,

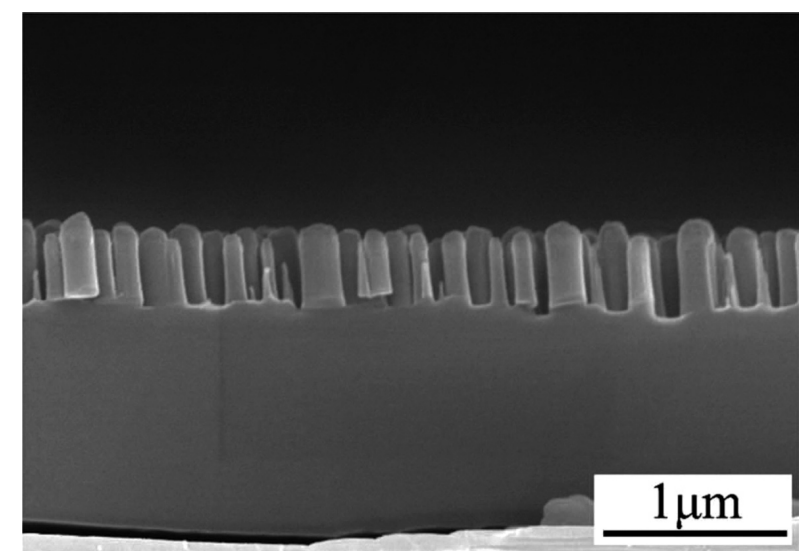

Figure 6: Cross-sectional SEM image of Si nanopillars formed after ICP etching for $1 \mathrm{~min}$ 
these small Ni nanodots eventually self-aggregate, enlarging their average diameter as the annealing time increases. The reason for this is the fact that a short annealing duration leads to an insufficient self-aggregation of a $\mathrm{Ni}$ film and therefore unevenly sized nanodots are formed. On the contrary, with the increase in the annealing time, the aggregation of a $\mathrm{Ni}$ film is sufficient, ${ }^{20}$ resulting in a fusion of small nanodots into larger ones. In this way, Ni nanodots with a uniform size and a regular spherical shape are easily obtained.

Si nanopillar arrays were prepared with the Ni-nanodot mask using inductively coupled plasma (ICP) etching method. The Ni-nanodot mask was obtained by conventionally annealing the $\mathrm{Ni}$ film $(22 \mathrm{~nm})$ at $800{ }^{\circ} \mathrm{C}$ for $1 \mathrm{~h}$. Figure 6 shows a side-view SEM image of the $\mathrm{Si}$ nanopillars formed after the ICP etching for $1 \mathrm{~min}$. It is, of course, necessary to continue optimizing the Ni mask and the dry-etching technique in the future. Nevertheless, this analysis gives us a good prospective of the abovementioned method so that we can prepare Ni-nanodot masks on Si substrates for practical applications.

\section{CONCLUSIONS}

We report on a simple and feasible method for preparing the Ni-nanodot mask on a $\mathrm{Si}$ substrate. The method was based on the conventional annealing of $\mathrm{Ni}$ films deposited on a silicon substrate using a common tube furnace instead of a high-cost RTA furnace. The size of nanodots became larger and their density was reduced with the increasing $\mathrm{Ni}$-film thickness or annealing temperature. The Ni film initially broke into large $\mathrm{Ni}$ strips, gradually obtaining a spherical shape with the increasing annealing time. Well-distributed Ni nanodots with a uniform size and a regular spherical shape were formed with this technique. Furthermore, we successfully fabricated a Si-nanopilliar array using inductively coupled plasma etching on the as-prepared Ni-nanodot mask.

\section{Acknowledgment}

This project was supported by the National Natural Science Foundation of China (Grant Nos. 51472061 and 51172054) and Shenzhen Selen Science \& Technology Co., Ltd.

\section{REFERENCES}

${ }^{1}$ L. M. Popescu, R. M. Piticescu, C. F. Rusti, M. Maly, A. Danani, S Kintzios, M. T. V. Grinan, Preparation and characterization of new hybrid nanostructured thin films for biosensors design, Mater. Lett., 65 (2011) 13, 2032-2035, doi:10.1016/j.matlet.2011.04.028

${ }^{2}$ U. Cvelbar, K. Ostrikov, A. Drenik, M. Mozetic, Nanowire sensor response to reactive gas environment, Appl. Phys. Lett., 92 (2008) 13, 133505, doi:10.1063/1.2905265

${ }^{3}$ F. Rana, S. Tiwari, J. J. Welser, Kinetic modelling of electron tunneling processes in quantum dots coupled to field-effect transistors,
Superlattices and Microstructures, 23 (1998) 3-4, 757-770, doi:10.1006/spmi.1997.0539

${ }^{4}$ N. M. Kalkhoran, F. Namavar, H. P. Maruska, Optoelectronic applications of porous polycrystalline silicon, Appl. Phys. Lett., 63 (1993) 19, 2661-2663, doi:10.1063/1.110412

${ }^{5}$ K. Kim, T. Moon, J. Kim, S. Kim, Electrically driven lasing in lightemitting devices composed of $\mathrm{n}-\mathrm{ZnO}$ and $\mathrm{p}-\mathrm{Si}$ nanowires, Nanotechnology, 22 (2011) 24, 245203, doi:10.1088/0957-4484/22/24/245203

${ }^{6}$ M. D. Henry, M.J. Shearn, B. Chhim, A. Scherer, Ga ${ }^{+}$beam lithography for nanoscale silicon reactive ion etching, Nanotechnology, 21 (2010) 24, 245303, doi:10.1088/0957-4484/21/24/245303

${ }^{7}$ G. H. Jeong, J. K. Park, K. K. Lee, J. H. Jang, C. H. Lee, H. B. Kang, C. W. Yang, S. J. Suh, Fabrication of low-cost mold and nanoimprint lithography using polystyrene nanosphere, Microelectron. Eng., 87 (2010) 1, 51-55, doi:10.1016/j.mee.2009.05.022

${ }^{8}$ W. J. Wang, G. F. Yang, P. Chen, Z. G. Yu, B. Liu, Z. L. Xie, X. Q. Xiu, Z. L. Wu, F. Xu, Z. Xu, X. M. Hua, H. Zhao, P. Han, Y. Shi, R. Zhang, Y. D. Zheng, Characteristics of nanoporous InGaN/GaN multiple quantum wells, Superlattices and Microstructures, 71 (2014), 38-45, doi:10.1016/j.spmi.2014.03.012

${ }^{9}$ T. Ignat, R. Munoz, K. Irina, I. Obieta, M. Mihaela, M. Simion, M. Iovu, Nanostructured Au/Si substrate for organic molecule SERS detection, Superlattices and Microstures, 46 (2009) 3, 451-460, doi:10.1016/j.spmi.2009.07.019

${ }^{10}$ H. W. Huang, J. T. Chu, C. C. Kao, T. H. Hseuh, T. C. Lu, H. C. Kuo, S. C. Wang, C. C. Yu, Enhanced light output of an InGaN/GaN light emitting diode with a nano-roughened p-GaN surface, Nanotechnology, 16 (2005) 9, 1844-1848, doi:10.1088/0957-4484/16/9/071

${ }^{11}$ J. Zhu, L. Wang, S. Zhang, H. Wang, D. Zhao, J. Zhu, Z. Liu, D. Jiang, H. Yang, The fabrication of GaN-based nanopillar light-emitting diodes, J. Appl. Phys., 108 (2010) 7, 074302, doi:10.1063/ 1.3488905

${ }^{12}$ L. Gong-Ru, K. Hao-Chung, L. Huang-Shen, K. Chih-Chiang, Rapid self-assembly of Ni nanodots on Si substrate covered by a lessadhesive and heat-accumulated $\mathrm{SiO}_{2}$ layers, Appl. Phys. Lett., 89 (2006) 7, 073108, doi:10.1063/1.2336081

${ }^{13}$ K. Mun Ja, L. Jin Seung, K. Seong Kyu, G. Y. Yeom, Y. Ji-Beom, P. Chong-Yun, Fabrication of Si nano-pillar array through Ni nano-dot mask using inductively coupled plasma, Thin Solid Films, 475 (2005) 1-2, 41-44, doi:10.1016/j.tsf.2004.07.026

${ }^{14}$ G. R. Lin, Y. C. Chang, E. S. Liu, H. C. Kuo, H. S. Lin, Low refractive index Si nanopillars on Si substrate, Appl. Phys. Lett., 90 (2007) 18, 181923, doi:10.1063/1.2736281

${ }^{15}$ G. R. Lin, C. J. Lin, H. C. Kuo, H. S. Lin, C. C. Kao, Anomalous microphotoluminescence of high-aspect-ratio Si nanopillars formatted by dry-etching Si substrate with self-aggregated Ni nanodot mask, Appl. Phys. Lett., 90 (2007) 14, 143102, doi:10.1063/ 1.2719152

${ }^{16}$ I. Levchenko, K. Ostrikov, K. Diwan, K. Winkler, D. Mariotti, Plasma-driven self-organization of Ni nanodot arrays on $\mathrm{Si}(100)$, Appl. Phys. Lett., 93 (2008) 18, 183102, doi:10.1063/1.3012572

${ }^{17}$ J. M. Lee, B. I. Kim, Thermal dewetting of Pt thin film: Etch-masks for the fabrication of semiconductor nanostructures, Mat. Sci. Eng. A-Struct., 449 (2007), 769-773, doi:10.1016/j.msea.2006.02.403

${ }^{18}$ J. W. Leem, Y. Yeh, J. S. Yu, Enhanced transmittance and hydrophilicity of nanostructured glass substrates with antireflective properties using disordered gold nanopatterns, Opt. Express, 20 (2012) 4, 4056-4066, doi:10.1364/OE.20.004056

${ }^{19}$ C. V. Thompson, Solid-State Dewetting of Thin Films, Annu. Rev. Mater. Res., 42 (2012), 399-434, doi:10.1146/annurev-matsci070511-155048

${ }^{20}$ Y. H. Pai, F. S. Meng, C. J. Lin, H. C. Kuo, S. H. Hsu, Y. C. Chang, G. R. Lin, Aspect-ratio-dependent ultra-low reflection and luminescence of dry-etched Si nanopillars on Si substrate, Nanotechnology, 20 (2009) 3, 035303, doi:10.1088/0957-4484/20/3/035303 